\title{
COMMENTARY
}

\section{Traumatic brain injury and resuscitation with blood products: what should we do?}

\author{
Bryan C Oh'1 and John B Holcomb*2 \\ See related research by Peiniger et al., http://ccforum.com/content/15/1/R68
}

\begin{abstract}
The study by Dr Peiniger and colleagues in a recent issue of Critical Care indicates that transfusion strategies using an early and more balanced ratio between fresh frozen plasma and red blood cell transfusions provide a survival benefit in patients with acute traumatic coagulopathy requiring massive transfusion within the first 24 hours of hospitalization. However, this topic has never been explored in depth in patients with concomitant severe traumatic brain injury. While the study is retrospective and certainly not a substitute for a well-designed prospective trial, the authors nonetheless should be commended for addressing this issue with their current work. Currently, the optimum fluid resuscitation paradigm for patients with both severe traumatic brain injury and other injuries requiring significant volume resuscitation is not clear.
\end{abstract}

As the study by Dr Peiniger and colleagues [1] correctly indicates, many retrospective studies have demonstrated a survival benefit from transfusion strategies using an early and more balanced ratio between fresh frozen plasma (FFP) and red blood cell (RBC) transfusions in patients with acute traumatic coagulopathy requiring massive transfusion within the first 24 hours of hospitalization. However, this topic has never been explored in depth in patients with concomitant severe traumatic brain injury (TBI). Previous studies have included these patients, but they were not the focus of investigation [2]. While the study by Dr Peiniger and colleagues is retrospective and certainly not a substitute for a well-designed prospective trial, the authors nonetheless should be commended for addressing this issue with their current

*Correspondence: John.Holcomb@uth.tmc.edu

${ }^{2}$ Center for Translational Injury Research, Department of Surgery, University of

Texas Health Sciences Center, Houston, TX 77030, USA

Full list of author information is available at the end of the article work. Currently, the optimum fluid resuscitation paradigm for patients with both severe TBI and other injuries requiring significant volume resuscitation is not clear. The Brain Trauma Foundation guidelines are silent on the issue of FFP:RBC ratios. Resuscitation and avoidance of hypotension is a primary goal, but the actual fluid within which to accomplish an optimal resuscitation is unknown. Bulger and colleagues [3] recently demonstrated that among injured patients with hypovolemic shock, initial resuscitation fluid treatment with either hypertonic saline or hypertonic saline/dextran compared with normal saline did not result in superior 28-day survival. The novelty of this current study is its focus on a high FFP:RBC ratio in resuscitation of profoundly hypovolemic TBI patients.

As the authors point out in their introduction, a major issue with these patients is coagulopathy at initial presentation. Coagulopathy in severe TBI patients can lead to profound hematoma expansion resulting in significant morbidity and mortality. A current active area of TBI research is the study of the mechanisms by which cerebral contusions expand. Additionally, TBI patients in general are susceptible to cytotoxic edema. Some feel these two events are related. Mechanisms that lead to cerebral edema in TBI patients are currently being actively investigated in the hope of developing treatment strategies to limit this problem and its sequelae.

Simard and colleagues [4] have reported data from rat studies that suggest that TBI leads to upregulation and activation of sulfonylurea receptor 1 (SUR1)-regulated $\mathrm{NC}(\mathrm{Ca}-\mathrm{ATP})$ channels in capillary endothelial cells, which predisposes them to oncotic death and catastrophic failure of capillary integrity. It is this failure of capillary integrity caused by upregulation of SUR1 expression that is hypothesized to cause development of progressive secondary hemorrhage. With unchecked progressive secondary hemorrhage, hematoma expansion can occur.

Ohsumi and colleagues [5] have also suggested that astrocytic gap junctions participate in pathophysiological processes after TBI in rats. Gap junctions are conductive channels formed by membrane proteins termed 
connexins, which permit the intercellular exchange of metabolites, ions, and small molecules. In this animal study, expression of the connexin $\mathrm{p}-\mathrm{Cx} 43$ in the ipsilateral hippocampus was significantly induced at 1 hour after TBI, and remained at a high level until 24 hours after injury. The $\mathrm{p}-\mathrm{Cx} 43$ protein content reached a maximum level at 6 hours after injury. This increased expression of $\mathrm{p}-\mathrm{Cx} 43$ suggests a mechanism by which ions and water could enter cells and lead to oncotic cell death.

A better understanding of the optimal resuscitation paradigm for hypovolemic patients with severe TBI could potentially help our understanding of both of these pathophysiological processes. A major barrier in the study of resuscitation of TBI subjects with concomitant hypovolemic shock is lack of a good animal model for the process. Development of a reliable animal model would be the first step in addressing this clinical problem. First, the animal model could address issues regarding the optimum fluid resuscitation regimen for hypovolemic, severe TBI patients. What is the role of crystalloid in this process? Which crystalloid should be used? Should FFP be the primary resuscitative fluid? And in patients requiring $R B C$ transfusion, what is the ideal FFP:RBC ratio? What is the role of lyophilized plasma? Such an animal model could potentially give us mechanistic clues and information as to why a specific resuscitation paradigm involving FFP is optimum. Is it possible that FFP resuscitation helps reverse the early coagulopathy seen in severely injured patients, and restore vascular stability, thus decreasing permeability and subsequent pathologic edema [6]? With good reproducible animal data and the retrospective data reported here by Peiniger and colleagues, it would then be important to design prospective studies to study this problem.

Ultimately, developing an optimum resuscitation paradigm for these patients could broaden our understanding of TBI pathophysiology in general. If a particular paradigm with a certain FFP:RBC ratio is shown to be superior to others, we would be in a position to understand why it is better. While many authors have described improved outcomes associated with increased FFP:RBC ratios, only now are mechanistic data starting to appear [7]. Perhaps a certain treatment may most effectively decrease mortality because it prevents unchecked progressive secondary hemorrhage. Alternatively, a given resuscitation paradigm may be superior because it is best at suppressing pathological expression of astrocytic gap junctions, thus decreasing edema progression. With both good animal data and results from prospective human studies in place, we should be in the position to significantly improve the care of severe TBI patients.

\section{Abbreviations}

FFP, fresh frozen plasma; RBC, red blood cell; TBI, traumatic brain injury.

\section{Competing interests}

The authors declare that they have no competing interests.

\section{Author details}

'Department of Neurosurgery, University of Texas Health Sciences Center, Houston, TX 77030, USA. Center for Translational Injury Research, Department of Surgery, University of Texas Health Sciences Center, Houston, TX 77030, USA.

Published: 22 July 2011

\section{References}

1. Peiniger S, Nienaber U, Lefering R, Braun M, Wafaisade A, Wutzler S, Borgmann M, Spinella P, Maegele M; the Trauma Registry of the Deutsche Gesellschaft für Unfallchirurgie (TR-DGU): Balanced massive transfusion ratios in multiple injury patients with traumatic brain injury. Crit Care 2011, 15:R68.

2. Holcomb JB, Wade CE, Michalek JE, Chisholm GB, Zarzabal LA, Schreiber MA, Gonzalez EA, Pomper GJ, Perkins JG, Spinella PC, Williams KL, Park MS: Increased plasma and platelet to red blood cell ratios improves outcome in 466 massively transfused civilian trauma patients. Ann Surg 2008, 248:447-458.

3. Bulger EM, May S, Brasel KJ, Schreiber M, Kerby JD, Tisherman SA, Newgard C, Slutsky A, Coimbra R, Emerson S, Minei JP, Bardarson B, Kudenchuk P, Baker A, Christenson J, Idris A, Davis D, Fabian TC, Aufderheide TP, Callaway C, Williams C, Banek J, Vaillancourt C, van Heest R, Sopko G, Hata JS, Hoyt DB; ROC Investigators: Out-of-hospital hypertonic resuscitation following severe traumatic brain injury: a randomized controlled trial. JAMA 2010, 304:1455-1464.

4. Simard JM, Kilbourne M, Tsymbalyuk O, Tosun C, Caridi J, Ivanova S, Keledjian K, Bochicchio G, Gerzanich V: Key role of sulfonylurea receptor 1 in progressive secondary hemorrhage after brain contusion. J Neurotrauma 2009, 26:2257-2267.

5. Ohsumi A, Nawashiro H, Otani N, Ooigawa H, Toyooka T, Shima K: Temporal and spatial profile of phosphorylated connexin43 after traumatic brain injury in rats. J Neurotrauma 2010, 27:1255-1263.

6. Pati S, Matijevic N, Doursout MF, Ko T, Cao Y, Deng X, Kozar RA, Hartwell E, Conyers J, Holcomb JB: Protective effects of fresh frozen plasma on vascular endothelial permeability, coagulation, and resuscitation after hemorrhagic shock are time dependent and diminish between days 0 and 5 after thaw. J Trauma 2010, 69 Suppl 1:S55-63.

7. Kozar RA, Peng Z, Zhang R, Holcomb JB, Pati S, Park P, Ko TC, Paredes A: Plasma restoration of endothelial glycocalyx in a rodent model of hemorrhagic shock. Anesth Analg 2011, 112:1289-1295.

doi:10.1186/cc10292

Cite this article as: Oh BC, Holcomb JB: Traumatic brain injury and resuscitation with blood products: what should we do? Critical Care 2011 15:172. 